\title{
O Plano Juventude Viva e a rede de políticas de juventude para enfrentamento à violência em Alagoas
}

\section{The Plano Juventude Viva and youth policies network to address violence in Alagoas}

\section{EI Plano Juventude Viva y la red de políticas de juventud para enfrentar la violencia en Alagoas}

\author{
Graciele Oliveira Faustino* \\ Universidade Federal de Alagoas - UFAL, Maceió, Alagoas, Brasil \\ Simone Maria Hüning** \\ Universidade Federal de Alagoas - UFAL, Maceió, Alagoas, Brasil
}

\begin{abstract}
RESUMO
Neste artigo, discutimos as políticas públicas de juventude para enfrentamento à violência, que estão sendo desenvolvidas em Alagoas. Utilizamos a Teoria Ator-Rede e considerando a implantação do Plano Juventude Viva (PJV) buscamos contribuir com o campo de estudo da juventude e políticas públicas, analisando especificamente as controvérsias em torno da constituição do público alvo e das propostas do referido plano em Alagoas. Nossa análise indica a imprecisão na delimitação do segmento da juventude a quem se destina o plano, a fragilidade da ação intersetorial e a falta de especificidade de intervenção desses programas sobre condições históricas de exclusão da juventude no estado, dentre as quais o racismo.

Palavras-chave: políticas públicas, juventude, violência, teoria ator-rede.
\end{abstract}

\section{ABSTRACT}

In this article we discuss public policies for young people to address violence, that are being developed in Alagoas. We used the ActorNetwork Theory and considering the implementation of the Plano Juventude Viva (Plan Youth Alive) we seek to contribute to the field of study of youth and public policy, specifically analyzing the controversies surrounding the constitution of the target audience and the proposals of the plan in Alagoas. Our analysis indicates the imprecision in defining the segment of the youth to whom the plan is intended, the fragility of intersectoral action and the lack of specificity of these intervention programs on historical conditions of exclusion of youth in the state, among which the racismo.

Keywords: public policy, youth, violence, actor-network theory.

\section{RESUMEM}

En este artículo se discuten las políticas públicas de juventud para enfrentar la violencia que se están desarrollando en Alagoas. Se utilizó la Teoría del 
Actor-Red y teniendo en cuenta la implementación del Plano Juventude Viva (Plan Juventud Viva) buscamos contribuir al campo de estudio de la juventud y las políticas públicas, analizando específicamente las controversias en torno a la constitución del público destinatario y las propuestas del plan en Alagoas. Nuestro análisis indica la imprecisión en la definición de segmento de la juventud a la que va dirigido el plan, la fragilidad de la acción intersectorial y la falta de especificidad de estos programas de intervención sobre las condiciones históricas de exclusión de los jóvenes en el estado, entre los cuales el racismo.

Palabras clave: políticas públicas, juventud, violencia, teoría del actor-red.

\section{Introdução}

Neste artigo, discutimos as políticas públicas de juventude para enfrentamento à violência, que estão sendo desenvolvidas em Alagoas, estado que se tornou território para projetos-piloto do governo federal, que têm como foco o combate à violência. Para tanto, recorremos à Teoria Ator-Rede (TAR); e a partir da implantação do Plano Juventude Viva (PJV) buscamos trazer uma contribuição para o campo de estudo da juventude e políticas públicas, analisando especificamente as controvérsias em torno da constituição do público alvo e das propostas do referido plano em Alagoas.

A TAR, desenvolvida por Bruno Latour, entre outros autores, sugere que as redes não são constituídas somente por pessoas, mas também por materiais não-humanos, formando redes heterogêneas. "O núcleo da abordagem ator-rede é o interesse por como atores e organizações mobilizam, justapõem e mantêm unidos os elementos que os constituem" (Law, 2001, s.p.); ou ainda, de acordo com Moraes (1998): "uma das contribuições do trabalho de Latour aos estudos sociais, bem como aos enfoques epistemológicos acerca da ciência é introduzir o não-humano no cerne de suas análises; nãohumano que é por definição impuro, híbrido" (p. 71).

A partir disso, pensamos nos entrelaçamentos e agenciamentos dos atores em rede, levando em conta o cenário atual, que situa Alagoas como um dos estados mais violentos do Brasil; a juventude, que é apontada como população mais vitimizada pela violência; e as ações do governo, voltadas para os jovens, com o objetivo de enfrentamento à violência. Seguir a rede de políticas para a juventude e discutir as formas de enfrentamento à violência implicaram em analisar o processo de fabricação de verdades sobre a população jovem e as políticas públicas, considerando os efeitos que tanto humanos, quanto não-humanos produzem na rede e que sustentam o direcionamento do Estado nas ações voltadas para os jovens. Estamos empregando o termo juventude quando nos referimos à população de jovens alvos de políticas públicas. 


\section{A Rede da pesquisa}

O estudo foi realizado na cidade de Maceió, em Alagoas no período de 2012 a 2013. Alagoas tem sido apontado como o estado mais violento e Maceió como uma das cidades mais violentas do Brasil. Dados recentes sobre violência foram apresentados principalmente nas últimas edições dos Mapas da violência (Waiselfisz, 2010, 2012a, 2012 b, 2013), e um destaque é feito à população jovem, visto que os jovens têm sido apontados como principais atores dessa violência, sejam como vítimas ou executores. Os índices de violência contabilizados nesses mapas referem-se à violência homicida, apontando um crescente número de homicídios de jovens, principalmente os jovens negros, pobres e de periferias. Esses índices de homicídios são frequentemente mencionados e usados como parâmetros para tratar da violência em Alagoas, sem que outras formas de violência, que também estão presentes no cenário alagoano, sejam suficientemente discutidas.

Os dados apresentados por estes mapas dão visibilidade à violência homicida, contribuindo na construção de um sentimento de insegurança, e põe em questão a atuação do Estado em relação à mesma. Somado a isso está a juventude como população mais atingida pela violência. A partir disso, podemos pensar se a juventude seria a parcela da população mais desassistida pelo governo, simplesmente em termos de segurança pública, ou se a violência seria produto da desassistência em outras áreas, tais como Saúde, Assistência e Educação.

Os Mapas da violência têm apresentado uma progressão da violência em Alagoas, principalmente na última década. Este estado, atualmente, aparece como primeiro colocado, no ordenamento das unidades federativas do país, em relação à violência, e Maceió como sendo a capital com maiores índices de homicídios tanto da população total, quanto da população jovem (15 a 29 anos) (Waiselfisz, 2012a). Em 2007, Alagoas aparece em 1 o lugar no ranking da violência por homicídios da população em geral (Waiselfisz, 2010), posição mantida nos anos seguintes, até o último mapa, lançado em 2014.

O Mapa de 2013, que analisa a violência no período de 2001 a 2011, apresenta Alagoas ocupando 0 1ㅇ lugar, dentre as unidades federativas, em relação a mortes por homicídios da população em geral, com uma taxa de 72,2. Sendo que em 2001, este estado apresentava uma taxa de homicídios de 29,3, ocupando o 12 o lugar. Isso demonstra que houve um aumento de $146,5 \%$ desse tipo de morte durante esta década (Waiselfisz, 2013). Quando se trata da população jovem, os dados são ainda mais alarmantes. A taxa de homicídios dos jovens em Alagoas subiu de 54,8, em 2001 (8o lugar), 
para 156,4, em 2011 (1ㅇ lugar), apresentando um aumento de $185,6 \%$, durante esta década. Ao analisar os índices de homicídios nas capitais dos estados, Maceió também recebe um destaque, por ter passado de 14ㅇ lugar, no ano de 1999, para o 1o em 2011 (Waiselfisz, 2013). A partir de dados como estes, Maceió tem sido apontada como uma das cidades, e a capital, mais violenta do país. Neste mesmo documento há uma discussão de que, apesar dos altos índices, as capitais têm apresentado um recuo na violência homicida, entre os anos de 2003 a 2011, em contraposição ao interior, que tem apresentado um crescimento dessa taxa. "O interior assume claramente o papel de polo dinâmico, motor da violência homicida, contrapondo-se às quedas substantivas nos níveis da violência que as Capitais estariam gerando" (Waiselfsz, 2013, pp. 49-50).

Em relação à amostra por municípios, no ano de 2011, que levou em conta municípios com mais de 20 mil habitantes, 15 deles ultrapassaram a marca de 100 homicídios por 100 mil habitantes. Destes quinze, seis estão em Alagoas: Arapiraca, Maceió, Marechal Deodoro, Pilar, Rio Largo e São Miguel dos Campos, ocupando respectivamente 5a $, 6^{a}, 15^{a}$ a, $8^{a}$ e $13^{a}$. Quando se trata da população negra, Alagoas apresenta, em 2011, uma taxa de 90,5 dos homicídios na população negra, de forma geral, e 201,2, na população jovem negra. Apresentou uma crescente de 650 homicídios de negros, em 2002, para 2.034, em 2011 (Waiselfisz, 2013), indicando que a população jovem negra é a mais vitimizada.

Estes dados se tornam modos de inscrição que materializam a violência de tal forma a ser apontada como um dos graves problemas do cotidiano em Alagoas, colocando em destaque determinada parcela da população (a juventude negra). De acordo com Latour (2001, p.350), inscrição é "um termo geral referente a todos os tipos de transformação que materializam uma entidade num signo, num arquivo, num documento, num pedaço de papel, num traço". A partir desta, entre outras materialidades, é possível pensar e questionar como estão se constituindo políticas públicas de juventude, voltadas para o enfrentamento da violência. Neste caso, a violência está sendo materializada através das estatísticas apresentadas de forma oficial em documentos; e os números são usados para indicar a presença ou não da violência num determinado local.

\section{Fundamentação teórico-metodológica}

De acordo com Latour (2012, p. 195), "para traçar um ator-rede, temos de acrescentar-Ihe os muitos traços deixados pelo fluido social graças ao qual possam reaparecer, desde que algo aconteça nele". Ou seja, um ator será identificado por sua "ação/atuação" na rede. Segundo Latour (2001, p. 143), "a única maneira de definir um ator é 
por intermédio de sua atuação; assim também, a única maneira de definir uma atuação é indagar em que outros atores foram modificados, transformados, perturbados [...]". O autor destaca também que "uma vez que, em inglês, a palavra 'actor' (ator) se limita a humanos, utilizamos muitas vezes 'actant' (atuante), termo tomado à semiótica, para incluir não-humanos na definição" (Latour, 2001, p. 346, grifo do autor).

A noção de rede proposta pela TAR permite o uso de associações de formação híbrida, compostas de materiais heterogêneos: humanos e não-humanos e discursos. Segundo Bonamigo (2008),

A rede é uma estrutura composta de elementos em interação, marcada por uma forte heterogeneidade, e se caracteriza tanto pelo conjunto de relações entre pontos ou nós, quanto por conexões e agenciamentos internos, não possuindo limites externos. Sua abertura possibilita crescer para todos os lados e direções. (Bonamigo, 2008, p. 351).

Por se tratar de uma rede de natureza heterogênea, temos que identificar o conjunto de ações realizadas na mesma; reconhecer que as conexões existentes na rede são formadas por sujeitos e objetos e, assim, tratá-los de forma simétrica. Latour não admite assimetria entre os atores e esclarece que,

O jogo não consiste em estender a subjetividade às coisas, tratar humanos como objetos, tomar máquinas por atores sociais e sim evitar a todo custo o emprego da distinção sujeito objeto ao discorrer sobre o entrelaçamento de humanos e nãohumanos. O que o novo quadro procura capturar são os movimentos pelos quais um dado coletivo estende seu tecido social a outras entidades. (Latour, 2001, p. 222).

Assim, nesta pesquisa, percorremos o que aqui estamos nomeando rede de políticas públicas de juventude para enfrentamento à violência, considerando as secretarias, os documentos, os funcionários, entre outros, como atores a serem tratados de forma simétrica. Dessa forma, deparamo-nos com o documento do "Plano Juventude Viva" como um ator, que levou a outros atores e permitiu identificá-los na rede.

A noção de tradução (também referida como translação) é importante para entendermos o engajamento ou ações e práticas dos atores na rede. Tradução (ou translação), para Latour (2000, p.178), é “[...] a interpretação dada pelos construtores de fatos aos seus interesses e aos das pessoas que a eles se aliam". Ainda segundo Latour (2001, p. 356) translação, "em suas conotações linguística e material, refere-se a todos os deslocamentos por entre outros atores cuja mediação é 
indispensável à ocorrência de qualquer ação". Dessa forma, as translações/traduções também são as apropriações de forma singular e local, que cada ator faz da rede. Assim, ao seguir os atores, o pesquisador tenta descrever as mediações existentes entre eles e faz um movimento de deslocamento, que possibilita tecer os fatos que compõem a rede e, de tradução em tradução, produzir um relato, por isso, como colocado por Pedro (2010, p. 83), "não há traduções 'certas' ou 'erradas', nem qualquer tradução deve ser tomada como 'indiscutível'".

Para a Teoria Ator-Rede, o termo "mediação", em contraste com "intermediário", significa um evento ou um ator que não podem ser exatamente definidos pelo que consomem e pelo que produzem. Se o intermediário é plenamente definido por aquilo que o provoca, uma mediação sempre ultrapassa sua condição (Latour, 2001, p. 351). Entendemos que os atores, enquanto mediadores, transformam, traduzem ou até modificam o que veiculam na rede.

De acordo com Bonamigo (2008, p. 350), a TAR “permite seguir a construção e fabricação de fatos e acompanhar atores sem imporIhes uma definição anterior". Assim, é possível descrever as associações heterogêneas sem reduzir seus efeitos a um único atorrede e as políticas públicas podem ser compreendidas como efeitos de associações de diversos atores, que engendram práticas e discursos. Aqui, portanto, buscamos identificar modos de inscrição que estão perpassando a fabricação de formas específicas de atuação do Estado junto aos jovens, neste cenário de violência, bem como as mediações, deslocamentos, vínculos dos atores das políticas públicas de juventude, para enfrentamento à violência em Alagoas.

Latour (2000) sugere que nos alimentemos de controvérsias na realização da pesquisa. Segundo o autor, devemos entrar no mundo da ciência "pela porta de trás", ou seja, pelo que ainda está em construção e, não pelo que já está pronto, acabado. Assim, as controvérsias servem como portas de entrada e quanto mais nos aproximamos, "mais as coisas se tornam controversas" (Latour, 2000 , p. 53). As controvérsias são, portanto, impasses, interrogações que não estão acabadas e que possibilitam a construção dos fatos. Tomamos essa proposta de análise das controvérsias científicas como referência para pensarmos a constituição de controvérsias na rede em questão.

$O$ estudo de controvérsias tem servido como ferramenta metodológica para compreender a constituição ciência-tecnologiasociedade. Nesse trabalho, a cartografia das controvérsias é utilizada como forma de mapear as conexões e mediações realizadas pelos atores na rede das políticas públicas para a juventude. É difícil definir de modo exato o é que controvérsia, mas nos aliamos a Pedro (2010, p. 87), ao sugerir que "de modo simples, podemos definir controvérsia como um debate (ou uma polêmica) que tem por 
'objeto' conhecimentos científicos ou técnicos que ainda não estão totalmente consagrados". Já a cartografia (neste caso, associada às controvérsias) "permite evidenciar o quanto os processos de construção do conhecimento se mesclam com os movimentos que constituem a própria rede" (Pedro, 2010, p. 89). Ainda de acordo com Pedro (2010, p. 82), "nos movimentos de composição das redes, os atores estão permanentemente traduzindo suas ações, linguagens, identidades e desejos, tendo em vista as mesmas manifestações em outros atores". Nesta pesquisa, a busca por políticas públicas de juventude permitiu identificar atores nesta rede, a partir de suas atuações.

Nesta pesquisa, consideramos ainda algumas regras metodológicas propostas por Latour (2000). Como primeira regra, devemos acompanhar os fatos em construção, então "não tentaremos analisar os produtos finais" (Latour, 2000, p. 39). Dessa forma, seguimos os atores da rede de políticas públicas de juventude não a tomando como um produto final, mas como objeto de controvérsias. Seguindo esse mesmo caminho, a violência aqui também é entendida como um processo, e não como produto final.

Na segunda regra, "para determinar a objetividade ou subjetividade de uma afirmação, a eficiência ou a perfeição de um mecanismo, não devemos procurar por suas qualidades intrínsecas, mas por todas as transformações que ele sofre depois [...]" (Latour, 2000, p. 421, grifo do autor). O que indica que procuramos as transformações das categorias que consideram objetivamente ou subjetivamente os jovens como alvos das políticas. Na terceira regra, Latour (2000, p. 421) esclarece que "[...] nunca podemos utilizar [...] a Natureza para explicar como e por que uma controvérsia foi resolvida". Logo, consideramos o processo de fabricação e as controvérsias existentes na rede, não naturalizando o que coloca esses jovens como alvos de políticas públicas, nem naturalizando a relação entre juventude e violência.

Para cumprir a quarta regra, “[...] devemos considerar simetricamente os esforços para alistar recursos humanos e nãohumanos" (Latour, 2000, p. 421). Ou seja, consideramos simetricamente os elementos dessa rede (documentos, secretarias, pessoas envolvidas etc.) e, como propõe Latour, "não usar a sociedade para explicar como e por que uma controvérsia foi dirimida" (2000, p.421). Na quinta regra, Latour (2000, p.289) propõe sermos tão indefinidos quanto os atores que seguimos. Se surgir uma divisão interior/exterior, "devemos acompanhar os dois lados simultaneamente [...] criando uma lista de todos aqueles que realizam trabalho". Aqui podemos pensar como abrimos controvérsias, quando estudamos políticas públicas de juventude e a violência, e por isso, realizamos uma descrição da rede sem predefinições. 
Como sexta regra, Latour (2000, p. 422) propõe olhar para “[...] o ângulo e a direção do deslocamento do observador, bem como para a extensão da rede que assim está sendo construída." Dessa forma, buscamos atentar para a extensão da rede e as conexões que compõem a mesma, seguindo as pistas dos atores e identificando suas conexões. E, por fim, "[...] examinaremos os muitos modos como as inscrições são coligidas, combinadas, interligadas e devolvidas" (Latour, 2000, p. 422). Ou seja, atentamos para diversos modos de inscrição que materializam esses jovens como problema para o Estado nessas políticas públicas, bem como as propostas de enfrentamento à violência aí constituídas.

As políticas públicas de juventude são pensadas como estratégias de governo para um determinado público, mas não podem ser pensadas sem levar em conta os diversos atores e seus agenciamentos, na constituição das mesmas. Ao tomar a violência como um produto final e como questão para pensar as políticas de juventude, o Estado reproduz uma naturalização da relação entre violência e juventude, com isso a própria política naturaliza o público alvo da violência, que neste caso é o jovem negro, pobre, de periferia.

\section{Percursos pela rede}

Para realizar a cartografia das controvérsias da rede de políticas públicas de juventude para enfrentamento à violência, seguimos em busca de atores dessa rede, para acompanhar as pistas que nos levassem a identificar os programas, ações e/ou projetos do governo direcionados aos jovens, com foco no combate à violência. Acolhemos narrativas sobre a assistência aos jovens em Alagoas, por meio de políticas públicas, mediante a reunião de documentos (do governo federal e estadual sobre políticas públicas de juventude) e de informações que dissessem respeito a essa rede de políticas.

Esse movimento de acompanhamento e descrição da rede se deu seguindo o fluxo das mediações entre os atores e das translações realizadas pelos mesmos. São atores nesta rede: secretarias estaduais, documentos de programas e planos do governo, sites da internet, superintendências, superintendentes, entre outros que apareceram ao longo do percurso. Ou seja, elementos, humanos e não-humanos, que tivessem algum agenciamento na rede.

Com base na TAR, para descrever a rede é necessário buscar portas de entradas, identificar os porta-vozes, acessar os dispositivos de inscrição e mapear as ligações da mesma. Inicialmente acessamos, por meio da internet, os documentos da Política Nacional de Juventude (PNJ) e do Guia Nacional de políticas públicas de juventude. Estes documentos serviram para nos inteirarmos dos 
eixos e discussões aos quais essas políticas estariam voltadas e para identificar como a juventude é apresentada nos mesmos.

Também foram acessados os portais do governo de Alagoas para conhecer as secretarias existentes e identificar aquelas que estivessem voltadas para execução de trabalhos que envolvessem políticas públicas, juventude e violência. A primeira secretaria acessada, por telefone, foi a Secretaria de Estado da Gestão Pública (SEGESP), a qual solicitamos informações sobre quais secretarias contatar, para a realização de pesquisa sobre políticas públicas de juventude. Então, direcionaram-nos à Secretaria de Governo, que indicou procurar a Secretaria do Estado de Assistência e Desenvolvimento Social (SEADES). Inicialmente, não foi fornecida nenhuma informação que levasse diretamente às políticas de juventude.

Pensamos então em procurar alguma secretaria ligada aos Direitos Humanos, em busca de outra porta de entrada. Assim, encontramos a Secretaria de Estado da Mulher, da Cidadania e dos Direitos Humanos (SEMCDH), à qual pertence a Superintendência de Políticas Públicas para a Juventude. Fomos diretamente a esta superintendência, onde foi possível conhecer a Superintendente de Políticas de Juventude do estado. Em diálogo com a mesma, ela fez uma breve explanação sobre a implantação deste órgão do governo e sobre as políticas para a juventude desenvolvidas em Alagoas, bem como sobre a carência de políticas para este segmento da população. Em um retorno à superintendência, com ofício de solicitação de liberação de documentos para a pesquisa, tivemos acesso ao documento "Plano Juventude Viva: plano de prevenção à violência contra a juventude negra".

No período inicial da pesquisa, em setembro de 2012, ocorreu o lançamento do Plano Juventude Viva (PJV) no estado de Alagoas, que definia como público-alvo os jovens (negros e da periferia) e tinha como foco de atuação o combate à violência. Este plano envolve diversas políticas e uma rede de articulação de ações, que está sendo fabricada a partir de discursos e práticas que envolvem uma população específica, a de jovens negros, pobres, das periferias, portanto não estamos falando de toda e qualquer juventude.

Vários discursos envolvendo juventude e violência foram apresentados, naquele momento, principalmente pela mídia local (televisiva, jornais escritos e online, além de sites diversos de notícias). No documento do PJV encontramos os programas e projetos do governo voltados para a juventude, levando em conta o enfrentamento à violência. Então, tomando como base este documento, que é um ator não-humano, e analisando as pistas fornecidas pelo mesmo, realizamos uma nova busca. Desta vez, por secretarias que estivessem ligadas ao plano. 
Recorrendo novamente à internet, conseguimos os telefones de contato das possíveis secretarias. Ao entrar em contato com a SEGESP, novamente, explicamos que se tratava de uma busca por programas voltados para a juventude, com foco no combate à violência. Então, desta vez, informaram-nos que deveríamos procurar a Secretaria de Direitos Humanos, a Secretaria da Paz, a Secretaria de Assistência Social e a Secretaria de Defesa Social. Como já havíamos contatado a SEMCDH, direcionamo-nos novamente à SEADES. No entanto, não souberam informar se havia programas com este objetivo e acrescentaram que se houvesse, seriam executados pela Secretaria Municipal de Assistência Social. Esta foi uma das primeiras controvérsias, pois, de acordo com o documento do Comitê Gestor do Plano Juventude Viva, a SEADES é uma das secretarias incluídas na execução das ações do plano. Assim, alguns programas ligados a esta secretaria estão incluídos nas estratégias de enfrentamento à violência, para o público juvenil, mas não são reconhecidos como tal.

Em outro momento, fomos à Secretaria de Estado da Defesa Social (SEDS). Ao explicar o motivo da visita, o senhor responsável pela recepção disse para "não perder tempo com isso" (sic) e falou sobre a questão da violência, alegando que a solução para a violência seria o aumento de efetivo da Polícia Militar e mais atuação desta nas ruas. Só depois de a pesquisadora falar que as informações fornecidas por ele seriam relevantes para a pesquisa, foi que o mesmo ligou para um setor, para verificar quem deveria ser consultado nesta secretaria. Neste momento, o telefone foi passado para a pesquisadora, para falar com uma pessoa da Assessoria de Comunicação (ASCOM), que indicou procurar uma tenente da Polícia Militar (Assistente Social). Esta, por sua vez, pediu que fosse agendado um dia para discutir as ações desenvolvidas pela SEDS. Uma observação merece destaque aqui. Na SEDS, diferentemente das outras secretarias, há uma catraca na recepção. Logo, só seria possível acessar alguém que pudesse fornecer mais informações com a liberação da catraca. Aqui retomamos Latour (2012, p. 118), que explica que "os objetos são muito bons em transmitir seus efeitos em silêncio". Então, surge a interrogação de como fazê-los "falar". De repente, aquela catraca e aquele senhor da recepção pareciam formar um único objeto; a catraca, somada a este senhor, teve o efeito de impedimento de acesso a algo. Este impedimento inicial leva-nos à ideia dos ditos e interditos, que atravessam o que é de interesse do governo e da sociedade, quando se trata de pesquisa e, no presente caso, dessa forma naturalizada de pensar a violência no estado e suas respectivas soluções. Além disso, é interessante apontar como a fala do referido senhor indica uma interdição e reitera a lógica da repressão, como forma de enfrentar a violência. Assim, acompanhar 
os atores é também se deparar com continuidades e descontinuidades, que podem aparecer na rede e/ou na pesquisa.

Em contato posterior com a referida tenente, agendamos um dia para pegar documentos sobre políticas públicas e ações do governo para enfrentamento à violência. Esta explicou como estavam sendo desenvolvidos os trabalhos de combate à violência na SEDS; falou das dificuldades de articulação com as demais secretarias e indicou procurar também a Secretaria de Estado de Promoção da Paz (SEPAZ) e a Superintendência de Políticas de Juventude (já acessada anteriormente). Indicou também o programa federal de combate às drogas "Crack, é possível vencer" e falou principalmente do êxito do trabalho da polícia comunitária e da necessidade de implantação e efetivação de políticas públicas de juventude. Dentre os documentos recebidos nesta secretaria, consta um relatório sobre o perfil das áreas para a implantação das bases comunitárias de segurança, que apresenta as áreas de vulnerabilidade e risco de Maceió. Os outros documentos fornecidos foram cartilhas do governo federal sobre o "Projeto J uventude e prevenção da violência".

Estes documentos nos dão pistas do que se tem pensado e elaborado em termos de estratégias de governo para o enfrentamento à violência que atravessa o cotidiano da juventude, mesmo quando não dizem respeito às políticas diretamente destinadas a este público. São documentos, portanto, que servem de pontos de questionamento sobre a problemática da violência e as ações do governo e, principalmente, servem para pensar como a juventude, mais especificamente a juventude negra e pobre, torna-se alvo de determinadas ações do governo.

Como houve duas indicações para procurar a SEPAZ, ao pensarmos nas convergências e divergências ocasionadas pelos conectores da rede, entramos em contato (por telefone) também com esta secretaria. No primeiro momento, não havia ninguém que pudesse passar as informações. No segundo contato com a SEPAZ direcionaram-nos a um dos superintendentes desta secretaria e conseguimos agendar uma data de visita à mesma. Durante a visita, em conversa com o superintendente, falou-se sobre a implantação desta secretaria e os programas executados através da mesma. Foinos informado que não havia nenhum programa específico para a juventude, pois as ações estavam voltadas para a população em geral e algumas delas focavam em trabalhos direcionados à infância, devido ao objetivo de implantação de uma cultura de paz e prevenção de violência para as futuras gerações de jovens.

O percurso de uma secretaria à outra e as formas de acesso a esses atores nos colocam diante do que Latour fala sobre precisarmos "ser capazes de seguir a continuidade regular de entidades heterogêneas e a descontinuidade completa entre os participantes, que, no fim, permanecerá incomensurável" (Latour, 2012, p. 115). À medida que 
seguimos as pistas dadas pelos atores, acompanhamos a extensão da rede, que cresce para todos os lados. Apesar do PJV englobar diversas secretarias, só algumas apareceram com atuações na rede.

É importante dizer que todo o percurso de busca pelos atores não se deu de forma rápida e contínua. Houve alguns intervalos de tempo, em vista dos contatos e possibilidades de acessos às secretarias. Como a rede pode se estender para todos os lados, a delimitação da extensão da rede nesta pesquisa foi estabelecida em virtude do tempo para realização da mesma. Assim, realizamos o acompanhamento de informações sobre o PJV durante o primeiro ano de adesão e implantação deste plano no estado. Concluímos a busca pelos elementos na rede em setembro de 2013, mas consideramos, conforme Latour (2012), que o relato e sua produção também a constituem.

Em setembro de 2013, por ocasião da comemoração de um ano de implantação do plano, foram realizadas reuniões entre governo e sociedade civil, com representantes dos governos estadual e federal, para discutir as ações do PJV. Primeiro, houve uma reunião entre os representantes do governo federal, gestores locais e comissão gestora estadual do plano e, posteriormente, uma reunião entre representantes do governo e a sociedade civil. Participamos da reunião aberta à sociedade civil e pudemos observar diferentes posicionamentos do governo e sociedade frente ao plano. Alguns participantes afirmaram que nada está sendo realizado; que não há de fato uma execução do PJV e houve cobrança por ações mais efetivas do governo. Após estes encontros, foi gerado um relatório contendo as ações executadas, os encaminhamentos e as ações em execução do PJV ao longo deste primeiro ano, que se encontra disponível no site da Secretaria Nacional de Juventude. Este percurso possibilitou acompanhar como estão sendo articulados os fatos sobre a violência envolvendo a juventude, em Alagoas. Tomamos o texto do PJV e as formas de acessá-lo e acessar os demais atores, como disparadores para analisarmos as controvérsias dessa rede.

\section{Resultados e discussão}

O PJV foi lançado, em caráter piloto, pelo governo federal, em Alagoas, com o intuito de combater a violência contra a juventude. De acordo com o documento, o plano "oferecerá um pacote de políticas sociais para o enfrentamento à violência, que se somará ao Plano Brasil Mais Seguro". O Programa Brasil mais seguro integra o Plano Nacional de Segurança Pública, do Ministério da Justiça, que visa a investigação sobre as mortes violentas e o controle de armas, e que promove o fortalecimento do policiamento ostensivo e comunitário. O piloto deste programa foi lançado em Alagoas, em 
junho de 2012, devido ao alto índice de homicídios no estado, o que reitera a naturalização da violência como sendo a violência homicida. A seleção de Alagoas como território de lançamento do plano se deve ao fato de esse estado "ocupar a primeira posição em taxas de homicídios do país" (Brasil, 2012, s.p.). O PJV define como objetivo principal "reduzir a vulnerabilidade da juventude negra à violência e prevenir a ocorrência de homicídios" (Brasil, 2012, s.p.). Entretanto, outros objetivos são identificados no documento do plano: "enfrentar a violência, problematizando a sua banalização e a necessidade de promoção dos direitos da juventude" e "promover os valores da igualdade [...]", entre outros (Brasil, 2012, s.p.).

O PJV reúne 30 iniciativas e 25 programas federais e envolve a articulação dos seguintes ministérios: Justiça, Saúde, Educação, Trabalho e Emprego, Cultura e Esporte. Em Alagoas as ações serão promovidas por meio das secretarias: de Estado da Mulher, da Cidadania e dos Direitos Humanos; da Educação e do Esporte; da Cultura; da Saúde; do Trabalho, Emprego e Qualificação Profissional; da Infraestrutura; da Defesa Social; da Assistência e Desenvolvimento Social; da Articulação Social; e da Promoção da Paz. Nacionalmente o PJV abrangerá 132 municípios e como piloto em Alagoas, inicialmente, atenderá 4 municípios: Maceió, Arapiraca, Marechal Deodoro e União dos Palmares. O mesmo está estruturado em torno de 4 eixos de atuação: desconstrução da cultura de violência; inclusão, oportunidades e garantia de direitos; transformação de territórios; e aperfeiçoamento institucional.

No PJV, a referência feita à juventude se dá em relação aos jovens na faixa etária entre 15 e 29 anos de idade, seguindo o instituído na Política Nacional de Juventude que, apesar de considerar que "a classificação etária serve apenas como um parâmetro social para o reconhecimento político da fase juvenil" (Novaes, Cara, Silva, \& Papa, 2006, p.5), acaba engendrando o entendimento sobre o que é a juventude para o Estado, visto que a delimitação da idade tem servido como um marcador operacional para a criação de políticas segmentadas para a população, permitindo que se delimite um público alvo de certas ações políticas. Especifica-se também que a população a ser assistida é a dos jovens negros, do sexo masculino, em sua maioria com baixa escolaridade, moradores de bairros mais afetados pela violência. População esta definida a partir de dados estatísticos, que apontam os jovens, homens, negros, pobres, de periferia como maiores vítimas de homicídios. Vemos, portanto, que a violência passa a ser associada a populações específicas e a determinados locais sem que se questione como ela se constituiu. $O$ problema passa a ser resumido a alguns tipos específicos de violências, tratados muitas vezes de forma descontextualizada. Deparamo-nos, então, com uma associação entre violência e pobreza remetida a diversos e constantes processos de naturalização aos 
quais muitos sujeitos são inscritos (naturalização da violência como sinônimo de homicídio - invisibilizando outras formas de violência; naturalização da relação entre juventude e violência; naturalização da relação entre pobreza e violência; e naturalização da relação entre violência e juventude negra e pobre). A exclusão não é tida como uma forma de violência, mas os excluídos são tidos como causadores da mesma.

No subtítulo do PJV lê-se "plano de prevenção à violência contra a juventude negra" e isso explicita que o plano tem como alvo a juventude negra, remetendo-nos à ideia de uma política de ação afirmativa para esta população. No entanto, ao longo do texto do plano, essa especificidade se perde, entre outros modos, diluída em outros públicos, aspecto controverso sobre o público-alvo. Encontramos várias formas de descrever o público a ser assistido no PJV: juventude, juventude negra, jovens, adolescente, jovens negros, organizações juvenis negras, jovens e demais segmentos da população, jovens quilombolas, e crianças, adolescentes e jovens. Além disso, o plano tem ações dirigidas também à população em geral, a mulheres, a pessoas com deficiência e a crianças e adolescentes. Outro ponto controverso presente no texto é que ao mesmo tempo em que se coloca que as ações se destinarão "aos jovens, principalmente aos jovens negros", se diz que "independente de raça/cor terão prioridade os jovens em situação de exposição à violência" (Brasil, 2012, s.p.).

O plano lista programas e projetos, apontando a definição, o valor dos recursos a serem investidos, os beneficiários, o meio de pactuação, as ações, o eixo de atuação e o ministério responsável por cada um deles. Assim temos a entrada de outros públicos contemplados pelas ações a serem desenvolvidas por estes programas, que passaram a integrar o PJV, como por exemplo, o Programa Segundo Tempo na Escola, que tem como público-alvo crianças e adolescentes.

Ao analisar a lista de ações do PJV, vemos que a maioria dos programas e projetos incluídos já existia antes da formulação do plano. Ou seja, no PJV fez-se um apanhado de programas do governo federal, agregando-os como projetos de governo para a juventude, com foco no enfrentamento à violência. Houve, portanto, uma articulação de programas e projetos das políticas de Saúde, Educação, Cultura, Justiça, Trabalho e Emprego e Esportes numa tentativa de dar conta de um problema complexo como a violência. $\mathrm{O}$ fato de estes programas terem sido criados com outros objetivos e implantados anteriormente ao PJV faz com que os mesmos não sejam vistos por alguns agentes executores destas políticas e pela sociedade civil como ações de enfrentamento à violência. Isso se evidenciou, não apenas em nosso percurso buscando identificar as secretarias de Estado responsáveis pelas políticas públicas para a 
juventude, mas também nos apontamentos feitos por membros da sociedade, na reunião de discussão de um ano de implantação do plano.

Embora possamos considerar desejável essa articulação indicada entre os diferentes setores (Saúde, Educação, Cultura, Justiça, Trabalho e Emprego e Esportes, etc.) nas estratégias de enfrentamento à violência, vemos que no entanto, conforme indicam os atores envolvidos nessa rede, essa ação intersetorial não se efetiva. Entendemos que isso ocorre não apenas por esses programas e projetos terem sido criados antes do PJV, mas porque há também um limite nessa articulação, dado pelos próprios processos de naturalização da violência e suas relações com a juventude pobre e negra. A articulação intersetorial deveria corresponder a uma compreensão de que a violência é produzida por múltiplos fatores, portanto, demandaria formas complexas e integradas de enfrentamento. No entanto, considerando os modos como vemos a violência ser naturalizada como fenômeno ligado a juventude negra e pobre das periferias, ousamos afirmar que essa articulação, vinculase mais ao interesse em defender projetos políticos do governo, do que de fato abordar a violência na sua complexidade, promovendo uma "juventude viva".

\section{Considerações finais}

A juventude, e mais especificamente a juventude negra, tem sido exposta a diversas formas de violação de direitos. As políticas sociais não estão sendo garantidas aos jovens vulneráveis socioeconomicamente. Além disso, deparamo-nos com um racismo estrutural que põe os jovens negros num quadro mais evidente de negação de acesso a estas políticas.

A edição do mapa da violência intitulada A cor dos homicídios (Waiselfisz, 2012b) compõem dados sobre a violência envolvendo a juventude negra no território alagoano, chamando a atenção para o fato de que, sobretudo a juventude negra é a mais atingida pela violência e que os crimes de homicídios também têm cor (e endereço). No mapa da violência de 2013, no que se refere à cor/raça, na população geral, a taxa de homicídios de brancos é de 8,1 , enquanto a taxa de homicídios de negros é de 90,5 . No que refere ao homicídio dos jovens, a taxa de homicídios de jovens brancos é de 15,5 e a de jovens negros é de 201,2. Assim, temos um estado que precisa enfrentar o problema da violência de forma geral e ainda o problema do racismo. Racismo este que é pouco dimensionado e é situado apenas em algumas ações do PJV, tais como os cursos de capacitação sobre racismo institucional, para os 
jovens quilombolas e para os profissionais das áreas de Saúde da Família e de Segurança pública.

Ao tomar o cenário de violência em Alagoas, surgem algumas inquietações: Como pensar em ações de enfrentamento à violência à juventude de forma geral e a uma juventude específica ao mesmo tempo? Como lidar com a violência e o racismo entrelaçados e vitimizando principalmente a população jovem negra? Essas questões têm um fundo maior quando recorremos à constituição histórica do nosso país e de Alagoas, marcada por um processo de exclusão dos negros, dos índios e dos pobres das comunidades rurais. O racismo é uma forma de violência que atinge diversas instâncias, e essa violência contra a juventude negra remonta ao processo de formação da nossa nação. Como diz Guimarães (2011, p. 309): "a situação de exposição contínua da juventude negra à violência tem raízes históricas".

A constituição do Brasil como nação é marcada pela história de escravidão de índios e negros. Pensemos, portanto, nos discursos e práticas que circunscrevem a trajetória dessas populações em nosso país, principalmente com a entrada da República e abolição da escravatura, em que, sustentados por saberes intelectuais, esses povos foram tratados como sendo inferiores e degenerados. Havia uma preocupação política em relação ao que fazer com os negros, pois estes eram vistos como perigosos. (Coimbra, 2001; Guimarães, 2012). Teorias racistas e eugênicas, que emergiram na Europa no século XIX, contribuíram para a disseminação de ideias sobre degenerescência associada ao povo negro e para a condenação da mistura das raças. Assim, mesmo com a abolição da escravatura, os negros continuaram a ser tratados como raça inferior e, ao serem relegados à pobreza, foram também associados à criminalidade. (Guimarães, 2012).

Este processo de marginalização dos negros, reforçado também pelo movimento higienista ocorrido na mesma época, demarcam a divisão da sociedade em classes sociais, atravessada por práticas violentas sustentadas por tais teorias. Segundo Guimarães (2011, pp. 309), “[...] a noção de raça ainda permeia o imaginário social brasileiro e tem sido utilizada para excluir ou alocar indivíduos em determinadas posições da estrutura social e também para deixa-los viver ou morrer".

O Estado, por vezes, dá garantias mínimas de sobrevivência, mas promove um abandono das vidas dessas populações. Assim, temos populações, como a juventude negra, vivendo em situação de exclusão e sendo vitimizada pela violência homicida. A violência que atravessou práticas de exclusão contra a população negra desde a escravatura se conecta com práticas atuais, de segmentação social, que coloca a população pobre e negra à margem e distante do acesso às políticas públicas e sociais em Alagoas. 
Vemos então um processo discriminatório em relação à população negra, herdado desde a época da escravidão. Movimentos reivindicatórios, por parte da população negra, foram muito importantes para a criação de políticas de ações afirmativas, como resposta a esse processo histórico e sistemático de violação de direitos desta população, envolta pela discriminação racial. Santos, Cavalleiro, Barbosa e Ribeiro (2008, p. 919) afirmam que "atualmente, tem se buscado desenvolver ações afirmativas a partir da intersetorialidade das políticas públicas nos diversos órgãos". Aparentemente, seria essa a proposta do PJV, que é organizado pela Secretaria Nacional de Juventude, Secretaria de Promoção da Igualdade Racial, além de ser uma proposta de cunho interministerial. Porém, o que pudemos acompanhar, ao percorrer a rede, foi a falta de comunicação entre as secretarias, e até mesmo de clareza sobre quem está envolvido nas políticas públicas, programas e projetos que constituem o plano.

As ações voltadas para a promoção de igualdade racial estão acontecendo a partir das tentativas e êxitos de diálogos com os governos (federal, estadual e municipais), mas não têm sido o suficiente para sanar o racismo e a desigualdade social que atravessam as vidas da população negra. Entendemos, a partir da TAR, que as políticas públicas, dentre as quais as ações afirmativas, foram e são constituídas de forma processual, pela ação de diversos atores. Portanto, todo esse movimento que constitui o processo histórico de violência contra a população negra e a formulação dessas políticas precisa ser acompanhado, seguido, para que seja possível identificar os nós que conectam tais atores e que possibilitam discutir as (des)continuidades das ações de governo para promoção da igualdade racial e enfrentamento das mais diversas formas de violência.

As controvérsias encontradas na rede percorrida nos levam a pensar que a formulação de algumas ações do governo, a especificação de um público a quem serão destinadas as mesmas, torna-se difícil à medida que essa especificação segmenta cada vez mais um público específico. Assim, temos um recorte de ações para a juventude (apontada de uma forma geral) e para a juventude negra. O que não se pode deixar de destacar é que, ao falar dos jovens alvos de ações do governo, trata-se de jovens das periferias, pobres e com pouco ou nenhum acesso às políticas sociais, tais como Educação, Saúde, Seguridade, entre outras. Seria, portanto, importante atentar para o fato de que os altos índices estatísticos não deveriam ser tomados como representações de uma realidade naturalmente violenta, mas como importantes indicadores da falta de acesso de determinados segmentos populacionais às políticas sociais.

Além disso, o PJV, em seu texto, por vezes parece agregar a juventude negra como mero cumprimento da agenda governamental. 
Então, vemos que os programas passarão a dar prioridade a este público, denunciando, assim, que o mesmo ficava de fora das ações do governo, e que agora será incluído, mas não se especifica de que forma isso será realizado. A dificuldade de definição do público do PJV (juventude como um todo ou juventude negra), para além do problema da violência, traduz uma resposta imediata do governo em relação a uma demanda específica, que foi sendo fabricada e materializada, tornando-se assim um problema de governo. Entendemos isso como uma controvérsia, que se desdobra na tradução deste plano, quando ao dirigir ações afirmativas aos jovens negros escapa a ideia de que se deve contemplar os dois públicos, que ora se hibridizam, ora se separam, num único plano governamental. No final das contas, esses públicos se entrelaçam na forma como se propõe a promoção de políticas públicas para a juventude centradas no fenômeno da violência, e da suposição de um elo intrínseco entre a pobreza e a marginalidade, que funciona como marcador para a operacionalização dessas políticas.

\section{Referências}

Bonamigo, I. S. (2008). Tecendo relatos, versões e cenas: etnografia de um evento violento. Psicologia \& Sociedade, 20(3), 350-359. Recuperado em 25 abril, 2014, de http://www.scielo.br/scielo.php?script=sci_arttext\&pid=S01027 $1822008000300005 \&$ Ing =en\&tlng=pt. $\quad$ 10.1590/S010271822008000300005

Brasil. (2012). Juventude Viva: plano de prevenção à violência contra a Juventude Negra. Secretaria Nacional de Juventude (S.I., s.p.).

Coimbra, C. (2001). Espaços urbanos e "classes perigosas". In C. Coimbra (Org.). Operação Rio: o mito das classes perigosas. Rio de Janeiro: Oficina do Autor, Niterói: Intertexto.

Guimarães, A. (2011). Juventude e segurança pública: dissonâncias e ressonâncias. In: F. Papa, \& M. V. Freitas (Orgs.). Juventude em pauta: políticas públicas no Brasil (pp.307-319). São Paulo: Petrópolis.

Guimarães, A. S. A. (2012). Preconceito racial: modos, temas e tempos ( 2 a ed.). São Paulo: Cortez.

Latour, B. (2000). Ciência em ação: como seguir cientistas e engenheiros sociedade afora (I. C. Benedetti, Trad.). São Paulo: UNESP. (Obra original publicada em 1987).

Latour, B. (2001). A esperança de pandora: ensaios sobre a realidade dos estudos científicos (G.C.C. de Sousa, Trad.). Bauru-SP: EDUSC. (Obra original publicada em 1999). 
Latour, B. (2012). Reagregando o social: uma introdução à teoria Ator-Rede (G.C.C. de Sousa, Trad.). Salvador: EDUFBA, São Paulo: EDUSC. (Obra original publicada em 2005).

Law, J. (2001). Notas sobre a Teoria do Ator-Rede: ordenamento, estratégia e heterogeneidade ( $\mathrm{F}$. Manso, Trad.). Retirado em 21 abril, 2014, de http://www.necso.ufrj. br/Trads/Notas\% 20sobre\% 20a\% 20teori a\% 20Ator-Rede.htm. (obra original publicada em 1992)

Moraes, M. O. (1998). Uma Psicologia em ação. Tese de Doutorado, Pontifícia Universidade Católica de São Paulo, São Paulo, SP, Brasil.

Novaes, R.C.R., Cara, D.T., Silva, D.M., \& Papa, F.C. (2006). Política Nacional de Juventude: diretrizes e perspectivas. Conselho Nacional de juventude. São Paulo: Fundação Friedech Ebert.

Pedro, R. (2010). Sobre redes e controvérsias: ferramentas para compor cartografias psicossociais. In: A. A. L. Ferreira, L. L. Freire, M. Moraes, \& J. J. Arendt (Orgs.). Psicologia e Teoria Ator-Rede (pp. 78-96). Rio de Janeiro: Nau.

Santos, S. A. dos, Cavalleiro, E., Barbosa, M. I, da S., \& Ribeiro, M. (2008). Ações afirmativas: polêmicas e possibilidades sobre igualdade racial e o papel do estado. Revista Estudos Feministas, 16(3), 913-929. Retirado em 21 abril, 2014, de http:// www.scielo.br/scielo.php?script=sci_arttext\&pid=S01040 $26 \times 2008000300012 \&|n g=e n \& t| n g=p t .10 .1590 /$ S0104026X2008000300012

Waiselfisz, J. J. (2010). Mapa da violência 2010 - Anatomia dos Homicídios no Brasil. São Paulo: Instituto Sangari. Retirado em 13 janeiro, 2014, de http://www.mapadaviolencia.org.br/mapa2010.php

Waiselfisz, J. J. (2012a). Mapa da violência 2012 - Crianças e adolescentes. Rio de Janeiro: CEBELA/FLACSO Brasil. Retirado em 13 janeiro, 2014, de http://www. mapadaviolencia.org.br/mapa2011.php

Waiselfisz, J. J. (2012b). Mapa da violência 2012 - A cor dos homicídios. Rio de Janeiro: CEBELA/FLACSO Brasil. Retirado em 21 novembro, 2013, de http://www.mapadaviolencia.org.br/pdf2012/mapa2012_cor.pd $f$

Waiselfisz, J. J. (2013). Mapa da violência 2013 - Homicídios e juventude no Brasil. Rio de Janeiro: CEBELA/FLACSO Brasil. Retirado em 11 agosto 2013, de http://www.mapadaviolencia.org.br/pdf2013/mapa2013_homici dios_juventude.pdf

Endereço para correspondência Graciele Oliveira Faustino 
Universidade Federal de Alagoas - Instituto de Psicologia

Av. Lourival Melo Mota, s/n, Cidade Universitária, CEP 57072-900, Maceió - AL, Brasil

Endereço eletrônico: gracipsi@yahoo.com.br

\section{Simone Maria Hüning}

Universidade Federal de Alagoas - Instituto de Psicologia

Av. Lourival Melo Mota, s/n, Cidade Universitária, CEP 57072-900, Maceió - AL, Brasil

Endereço eletrônico: simonehuning@yahoo.com.br

Recebido em: 30/04/2014

Reformulado em: 18/08/2014

Aceito para publicação em: 04/09/2014

\section{Notas}

* Psicóloga e Mestre em Psicologia pela Universidade Federal de Alagoas.

** Doutora em Psicologia. Docente-Pesquisadora do Instituto de Psicologia da Universidade Federal de Alagoas. 